\title{
Electrical Stimulation in Addition to Passive Exercise Has a Small Effect on Spasticity and Range of Motion in Bedridden Elderly Patients: A Pilot Randomized Crossover Study
}

\author{
Hideki Kataoka1,2, Shunpei Nakashima1, Hideki Aoki', Kyo Goto' ${ }^{1}$, Junichiro Yamashita1, \\ Yuichiro Honda2,3, Yasutaka Kondo4, Tatsuya Hirase ${ }^{2,5}$, Junya Sakamoto2,5, Minoru Okita2,5* \\ ${ }^{1}$ Department of Rehabilitation, Nagasaki Memorial Hospital, Nagasaki1, Japan \\ ${ }^{2}$ Department of Physical Therapy Science, Nagasaki University Graduate School of Biomedical Sciences, Nagasaki, Japan \\ ${ }^{3}$ Department of Rehabilitation, Nagasaki University Hospital, Nagasaki, Japan \\ ${ }^{4}$ Department of Rehabilitation, Nagasaki Genbaku Hospital, Nagasaki, Japan \\ ${ }^{5}$ Institute of Biomedical Sciences, Nagasaki University, Nagasaki, Japan \\ Email: kataoka-hide@kii.bbiq.jp, P0911051@kio.ac.jp, hideki7486416@yahoo.co.jp, gottsu_hibiku@yahoo.co.jp, \\ nmhriha@ngs2.cncm.ne.jp, yhonda@nagasaki-u.ac.jp, yasukon48@yahoo.co.jp, htatsuya@nagasaki-u.ac.jp, \\ jun-saka@nagasaki-u.ac.jp *mokita@nagasaki-u.ac.jp
}

How to cite this paper: Kataoka, H., Nakashima, S., Aoki, H., Goto, K., Yamashita, J., Honda, Y., Kondo, Y., Hirase, T., Sakamoto, J. and Okita, M. (2019) Electrical Stimulation in Addition to Passive Exercise Has a Small Effect on Spasticity and Range of Motion in Bedridden Elderly Patients: A Pilot Randomized Crossover Study. Health, 11, 1072-1086.

https://doi.org/10.4236/health.2019.118084

Received: July 12, 2019

Accepted: August 17, 2019

Published: August 20, 2019

Copyright $\odot 2019$ by author(s) and Scientific Research Publishing Inc. This work is licensed under the Creative Commons Attribution International License (CC BY 4.0).

http://creativecommons.org/licenses/by/4.0/

\begin{abstract}
Purpose: Belt electrode skeletal muscle electrical stimulation (B-SES) can stimulate large portions of muscles including deep sites without localisation of the stimulation area. The purpose of this study is to investigate both immediate treatment effects of B-SES and long-term treatment effects of B-SES with passive exercise on range of motion (ROM) and muscle tone of lower extremities in bedridden elderly patients. Methods: Outcome measures before and after B-SES treatment alone (4 Hz, $20 \mathrm{~min}$, both lower extremities) were examined for the immediate effect. Outcome measures were: ROM and Modified Ashworth scale (MAS) of hip flexion and adduction; knee flexion and extension; and knee joint distance at position of flexion abduction in hip (distance of knee). A randomized crossover trial was conducted to examine the long-term effect of adding B-SES to passive exercise on ROM and MAS. Results and Discussion: The immediate effect study had 18 patients. ROM and MAS of 4 joint angles in 2 joints and distance of knee significantly improved after B-SES treatment. The long-term effect study had 11 patients. Friedman test revealed ROM and MAS of 4 joint angles in 2 joints and distance of knee significantly improved during B-SES intervention but not control intervention. B-SES in addition to passive stretch has a more statistically significant effect on contracture and spasticity in large portions of the lower
\end{abstract}


extremities of bedridden elderly patients than passive stretching alone. Conclusions: We consider B-SES a useful tool to improve the ROM in lower extremities of bedridden patients.

\section{Keywords}

Bedridden Patients, Belt Electrode Skeletal Muscle Electrical Stimulation, Lower Extremity, Muscle Tone, Restriction of Range of Joint Motion

\section{Introduction}

Elderly patients who are confined to bed in long-term care (LTC) facilities represent one of the most vulnerable populations. These elderly patients have severe contractures due to the immobilization associated with prolonged bed rest [1]-[6]. Contractures are understood to be an alteration in the viscoelastic properties of periarticular connective tissue including the muscles. This alteration can potentially lead to a reduction in the range of motion (ROM) in a joint or an increased resistance to passive joint movement, which in turn reduces joint flexibility and mobility [6] [7] [8]. Elderly patients confined to bed in LTC facilities often have neurological disorders that lead to the development of contracture. For example, an upper motor neuron syndrome resulting from a stroke can cause spasticity. Spasticity is characterised by a velocity-dependent increase in tonic stretch reflexes (muscle tone) with an exaggerated tendon reflex due to the hyperexcitability of the stretch reflex [7] [9]. Thus, spasticity disrupts the remaining functional use of the muscles, impedes motion, and may cause pain, which in turn impairs motor function [10] and might contribute to the development of contractures [11] [12]. Both contracture and spasticity can reduce ROM and activity [13] [14] [15].

Effective interventions for restrictions of ROM induced by contracture and spasticity are currently limited. Full ROM exercises of the upper and lower extremities with stretching are identified as an effective method to improve ROM in bedridden older stroke survivors in LTC facilities [16]. However, it is reported that stretching does not have clinically significant effects on joint mobility [17]. Electrical stimulation is a tool which can immediately reduce spasticity [18] [19]. Furthermore, the addition of electrical stimulation to stretching or standardized physical therapy leads to reduced spasticity and improved ROM in patients with spinal cord injury or children with cerebral palsy [18] [20]. In addition, electrical stimulation combined with other intervention treatment techniques is more effective for ROM and spasticity than intervention treatment techniques only [21]. Electrical stimulation devices used in previous reports were the conventional pad-use type. However, it is difficult to apply pad-use type electrical stimulation devices to patients who are confined to bed in LTC facilities, because they have restriction of ROM in almost every joint in their lower extremities such as flex- 
ion, extension, adduction, abduction, internal and external rotations, and dorsal and plantar flexions at the hip, knee, and ankle joints.

Belt electrode skeletal muscle electrical stimulation (B-SES) can stimulate large portions of muscles including deep sites without localisation of the stimulation area [22]. Prolonged low-intensity B-SES training resulted in significant increases in muscle strength and cardiorespiratory fitness in healthy subjects. There are no reports about the effect of B-SES on ROM and muscle tone. It is clinically important to examine the effects of B-SES training on reducing muscle tone and restriction of joint ROM.

In this study, we investigated both the immediate treatment effects of B-SES and the long-term treatment effects of adding B-SES to passive exercise such as stretching, on muscle tone and contracture in patients who were confined to bed in LTC facilities.

\section{Methods}

The study protocol was approved by the Research Ethical Committee at the Graduate School of Biomedical Sciences at Nagasaki University (approval number: 16060914-2). Our study was registered in the University Hospital Medical Information Network (UMIN) (Registration number: UMIN000026808). However, the registration date was retrospective to patients' enrollment.

\subsection{Experiment 1}

To examine the immediate treatment effects of B-SES, we performed outcome measures before and after B-SES treatment alone.

\subsubsection{Patients}

Participants were bedridden patients recruited from LTC facilities of Nagasaki Memorial Hospital, Nagasaki, Japan from June 2016 to December 2017. Rehabilitation consisted of passive ROM exercise and sitting or standing that was provided three times per week for all patients before this study started. To be included, the patients' frailty status was assessed by the Canadian Study of Health and Aging (CSHA)-Clinical Frailty Scale [23]. This tool is based on the judgment of clinicians and has been validated in a population-based study of Canadian seniors. This tool classifies older adults as very fit (level 1), well (level 2 ), well with treated comorbidities (level 3), apparently vulnerable (level 4), mildly frail (level 5), moderately frail (level 6), or severely frail (level 7). The patients included in our study were required to be severely frail (level 7), thus, their activities of daily living were disturbed and they could not roll, rise up, sit, stand, and walk independently. The patients were required to have restricted range of passive motion in their lower extremities. Patients were excluded if they had severe complications that could inhibit rehabilitation (i.e. haemodynamically unstable, severe infection, and severe impaired consciousness) or were contraindicated to the electrical stimulation (i.e. a pacemaker and dermal fragility). 
Before study entry, demographic characteristics of participants such as age, gender, disease, Clinical Frailty Scale, nutrition management and length of hospitalization were collected and baseline evaluations of the ROM and muscle tone were conducted. All patients provided informed consent prior to study entry. If it was difficult for the patient to understand the explanation and purpose of the study, informed assent was provided.

\subsubsection{Intervention}

B-SES treatment was applied to both lower extremities of the participants (Figure 1). B-SES treatments used 6 silicon-rubber electrode bands that were wrapped around the bilateral proximal and distal parts of the thigh and secured with Velcro-straps [22]. B-SES was applied to the quadriceps, hamstrings, and triceps surae on each lower extremity. Auto Tens Pro (Homer ion, Tokyo, Japan) was used as the stimulator. The frequency of stimulation was $4 \mathrm{~Hz}$, and the pulse width was $0.25 \mathrm{~ms}$. The intensity was set at as high a level as the participant would tolerate and that would produce visible contraction. B-SES treatment was applied for $20 \mathrm{~min}$.

\section{Outcome measures}

Before and after B-SES treatment, outcome measures were collected by 2 experienced physiotherapists who were not blinded. The outcome measures for contractures were 4 joint angle measurements in 2 joints that were assessed by a goniometer: hip flexion and adduction; and knee flexion and extension. In addition, the distance between both knee joints at the position of flexion abduction in the hip (distance of knee) was measured using a tape measure. Muscle tone was also assessed, while the therapists measured the range of joint motion, using

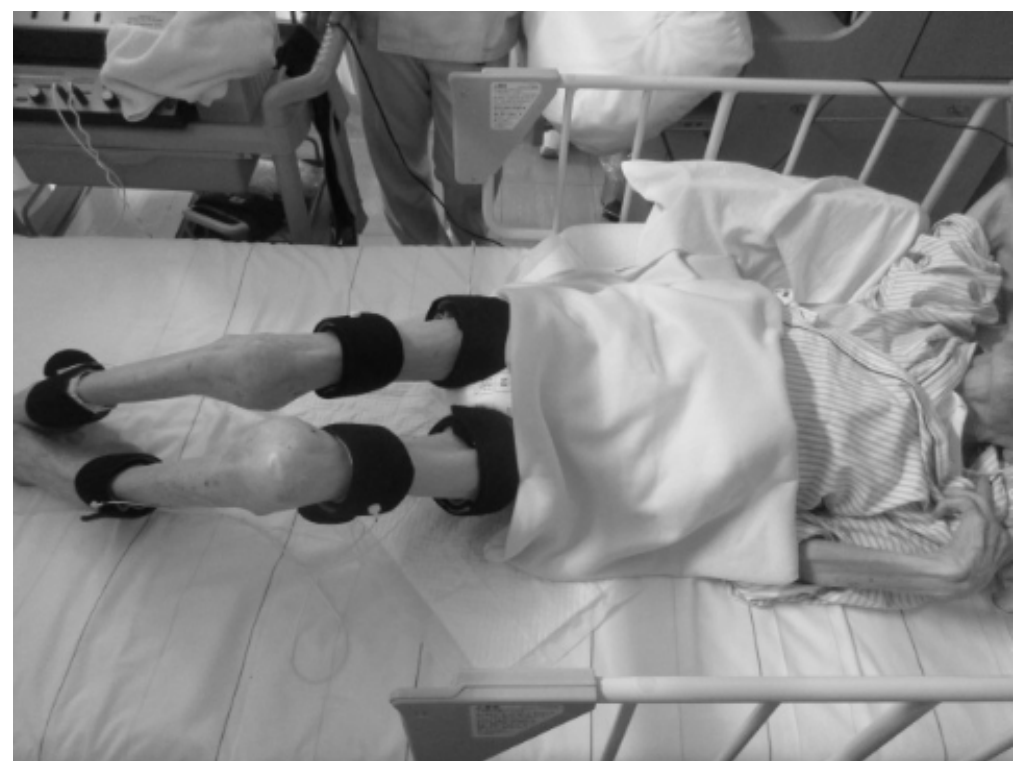

Figure 1. B-SES treatment for participants' lower extremities. Six silicon-rubber electrode bands were wrapped around bilateral proximal and distal parts of thigh and secured with Velcro-straps. B-SES was applied to quadriceps, hamstrings, and triceps surae muscles on each lower extremity. 
the Modified Ashworth scale (MAS) [24]. The MAS of each direction of motion was evaluated by rapid repetitive passive joint movement.

\subsubsection{Data Analysis}

The change from pre-B-SES treatment to post-B-SES treatment for each of the outcome measures was compared using the Wilcoxon signed-rank test. Statistical analyses were performed using SPSS for Windows version 22.0. An arbitrary level of 5\% statistical significance (two-tailed) was assumed, and the data were reported as the mean \pm standard deviation.

\subsection{Experiment 2}

\subsubsection{Design}

To examine the long-term effects of adding B-SES to stretching, a randomized crossover trial was conducted. At the initial assessment, the treating physiotherapist randomly selected patients to be in group A or B by computer-generated randomization lists after baseline measurements were completed. Patients in group A were treated with passive exercise consisting of stretching, sitting, and standing 3 times per week for 12 weeks (control period). Then, after a 2-week washout period, group A patients were treated with B-SES followed by passive exercise 3 times per week for another 12 weeks (intervention period). Patients in group B were treated with B-SES followed by passive exercise 3 times per week for 12 weeks (intervention period). Then, after a 2 -week washout period, group B patients were treated with passive exercise 3 times per week for another 12 weeks (control period). To minimize any possible carryover effect between periods in this crossover trial, investigators used a 2 -week "washout" phase that was sufficiently long to eliminate the first treatment's effects.

\subsubsection{Patients}

Participants were bedridden patients recruited from LTC facilities of Nagasaki Memorial Hospital, Nagasaki, Japan from June 2016 to December 2017. Inclusion and exclusion criteria were the same as in Experiment 1. Before study entry, demographic characteristics of participants and baseline evaluations same as Experiment 1 were collected. All patients provided informed consent or assent prior to study entry. We designed this study to detect an effect size of 1.05 , according to the results of previous study [25]. It was determined that 12 legs (6 patients) per group were needed to achieve $80 \%$ power for significant between-group difference at an $\alpha$ level of 0.05 .

\subsubsection{Intervention}

During the intervention periods, B-SES treatments and passive exercise were applied 3 times per week. B-SES treatment was the same method as in Experiment 1. After B-SES treatment, 20 min of passive exercise consisted of full ROM movements in three joints (hip, knee, and ankle) including flexion, extension, adduction, abduction, internal and external rotations, dorsal and plantar flexions, and sitting or standing. 
During the control periods, 20 min of passive exercise, as stated above, was applied 3 times per week.

\subsubsection{Outcome Measures}

In the control and intervention periods, outcome measures were collected by 2 experienced physiotherapists who were not blinded to intervention allocation at week 0 (baseline), week 4 , week 8 , and week12. In the intervention period, however, outcome measures were conducted immediately after the first intervention for both groups to examine the immediate effect of B-SES treatment. Outcome measures were conducted in a similar way as Experiment 1.

\subsubsection{Data Analysis}

Variables were compared between the allocated sequence using the independent t-test for continuous variables and Chi-squared or Mann-Whitney $U$ tests for the categorical variables. The mean percentage changes obtained at the end of the B-SES intervention were compared with the results at the end of the control intervention using the paired Student $t$-test for the ROM and distance of knee data, and the Wilcoxon signed-rank test for MAS. To identify carryover, the period and treatment effects of B-SES intervention, data of ROM and MAS of each joint, and movement at 3 months in Period 1 or 2 were used. The sum of data in each period was compared between groups A and B to analyse carryover effect. Half of each period difference was compared between group A (period 2-period 1) and B (period 1-period 2) to analyse period effect. Half of the difference between period 1 and 2 (period 1-period 2) was compared between groups A and B to analyse treatment effect. The carryover period and treatment effects were tested using the appropriate Student $\mathrm{t}$-test.

The MAS and ROM data of the control period of groups A and B (22 legs) were used to identify the effect of passive exercise only. On the other hand, the MAS and ROM data of the intervention period of groups A and B (22 legs) were used to identify the effect of B-SES + passive exercise only. Friedman's test was used for this analysis.

Statistical analyses were performed using SPSS for Windows version 22.0. An arbitrary level of $5 \%$ statistical significance (two-tailed) was assumed, and the data were reported as the mean \pm standard deviation.

\section{Results}

\subsection{Experiment 1}

We enrolled 18 patients ( 10 female) for a total of 36 lower extremities in Experiment 1 , and Table 1 summarizes the patients' characteristics. All patients were scored 7 by the CSHA Clinical Frailty Scale.

The data showing the immediate effects of B-SES treatment at 2 measurement times (pre- and post-B-SES treatment) are presented in Table 2. The mean improvement of ROM by the treatment was $4.2^{\circ} \pm 1.1^{\circ}, 3.9^{\circ} \pm 0.8^{\circ}, 1.9^{\circ} \pm 0.5^{\circ}, 3.1^{\circ}$ $\pm 1.0^{\circ}$, and $3.1 \pm 0.5 \mathrm{~cm}$ for hip flexion, abduction, knee flexion, knee extension, 
Table 1. Patients' characteristics included to examine the immediate effect of B-SES.

\begin{tabular}{|c|c|c|}
\hline \multicolumn{2}{|r|}{ Characteristics } & Mean $\pm \mathrm{SD} / \mathrm{n}$ \\
\hline \multicolumn{2}{|r|}{ Age } & $81.7 \pm 9.27$ \\
\hline \multicolumn{2}{|c|}{ Gender (men/women) } & $8 / 10$ \\
\hline \multicolumn{2}{|r|}{ BMI $\left(\mathrm{kg} / \mathrm{m}^{2}\right)$} & $16.7 \pm 1.9$ \\
\hline \multirow[t]{5}{*}{ Disease } & Cerebral infarction & 12 \\
\hline & Cerebral hemorrhage & 2 \\
\hline & Subarachnoid hemorrhage & 1 \\
\hline & Hypoxic ischemic encephalopathy & 1 \\
\hline & Pneumonia & 2 \\
\hline \multirow[t]{2}{*}{ Nutrition management } & Enteral nutrition (oral/tube) & $2 / 14$ \\
\hline & Parenteral nutrition & 2 \\
\hline \multicolumn{2}{|c|}{ Length of hospitalization (days) } & $1202.6 \pm 977.0$ \\
\hline
\end{tabular}

Abbreviations: SD: standard deviation; BMI: body mass index.

Table 2. Immediate effect of B-SES for ROM and MAS.

\begin{tabular}{|c|c|c|c|c|c|c|c|c|c|c|}
\hline \multirow[b]{2}{*}{ ROM } & \multicolumn{2}{|c|}{ Hip flexion $\left({ }^{\circ}\right)$} & \multicolumn{2}{|c|}{ Hip abduction $\left({ }^{\circ}\right)$} & \multicolumn{2}{|c|}{ Knee flexion $\left({ }^{\circ}\right)$} & \multicolumn{2}{|c|}{ Knee extension $\left({ }^{\circ}\right)$} & \multicolumn{2}{|c|}{ Knee distance $(\mathrm{cm})$} \\
\hline & Before & After & Before & After & Before & After & Before & After & Before & After \\
\hline Mean & 97.6 & 101.8 & 15.8 & 19.7 & 142.9 & 144.9 & -40.1 & -37.1 & 32.3 & 35.4 \\
\hline $\mathrm{SD}$ & 14.1 & 16.6 & 10.9 & 10.8 & 16.4 & 16.5 & 29.6 & 28.0 & 13.3 & 13.6 \\
\hline $95 \% \mathrm{CI}$ & $95-105$ & $100-110$ & $15-20$ & $20-25$ & $145-150$ & $145-155$ & $-50--20$ & $-45--20$ & $24-42$ & $27.5-47$ \\
\hline $\mathrm{p}$ & \multicolumn{2}{|c|}{$\mathrm{p}=0.0002$} & \multicolumn{2}{|c|}{$\mathrm{p}<0.0001$} & \multicolumn{2}{|c|}{$\mathrm{p}=0.0006$} & \multicolumn{2}{|c|}{$\mathrm{p}=0.004$} & \multicolumn{2}{|c|}{$\mathrm{p}<0.0001$} \\
\hline MAS & Before & After & Before & After & Before & After & Before & After & Before & After \\
\hline Mean & 2.0 & 1.6 & 3.1 & 2.7 & 1.5 & 1.2 & 1.4 & 0.9 & 3.2 & 2.8 \\
\hline SD & 1.7 & 1.6 & 1.5 & 1.5 & 1.7 & 1.5 & 1.5 & 1.4 & 1.4 & 1.4 \\
\hline $95 \% \mathrm{CI}$ & $1-4$ & $0-3$ & $3-4$ & $3-4$ & $0-3$ & $0-1$ & $0-2$ & $0-1$ & $2-4$ & $1-4$ \\
\hline $\mathrm{p}$ & \multicolumn{2}{|c|}{$\mathrm{p}=0.0004$} & \multicolumn{2}{|c|}{$\mathrm{p}=0.0028$} & \multicolumn{2}{|c|}{$\mathrm{p}=0.008$} & \multicolumn{2}{|c|}{$\mathrm{p}=0.0006$} & \multicolumn{2}{|c|}{$\mathrm{p}=0.0078$} \\
\hline
\end{tabular}

Abbreviations: ROM: range of motion; MAS: modified Ashworth scale; SD: standard deviation; 95\%CI: 95\% confidence Interval.

and distance of knee, respectively. The mean \pm SD decrease in the MAS score by the treatment was $-0.39 \pm 0.11$ points, $-0.39 \pm 0.13$ points, $-0.3 \pm 0.15$ points, $-0.44 \pm 0.14$ points, and $-0.44 \pm 0.12$ points for hip flexion, abduction, knee flexion, knee extension, and distance of knee, respectively. There was a statistically significant difference between pre- and post-B-SES treatment.

\subsection{Experiment 2}

The flow chart in Figure 2 outlines this study's recruitment of patients and randomization into the 2 study groups. Sixteen patients were recruited and randomly allocated to either group A $(n=8)$ or group B $(n=8)$. Three patients in group A withdrew from the trial; 2 patients refused to continue with the experi- 
ment; and 1 patient refused the evaluation of ROM and muscle tone. Two patients in group B withdrew from the trial, because they refused to continue with the experiment. There were no significant group differences in the study withdrawal. Eleven participants completed the 6-month intervention with 5 in group A and 6 in group B. No adverse events related to B-SES were observed. Table 3 shows Patients' characteristics included to examine the long-term effect of B-SES. All patients were scored 7 by the CSHA Clinical Frailty Scale.

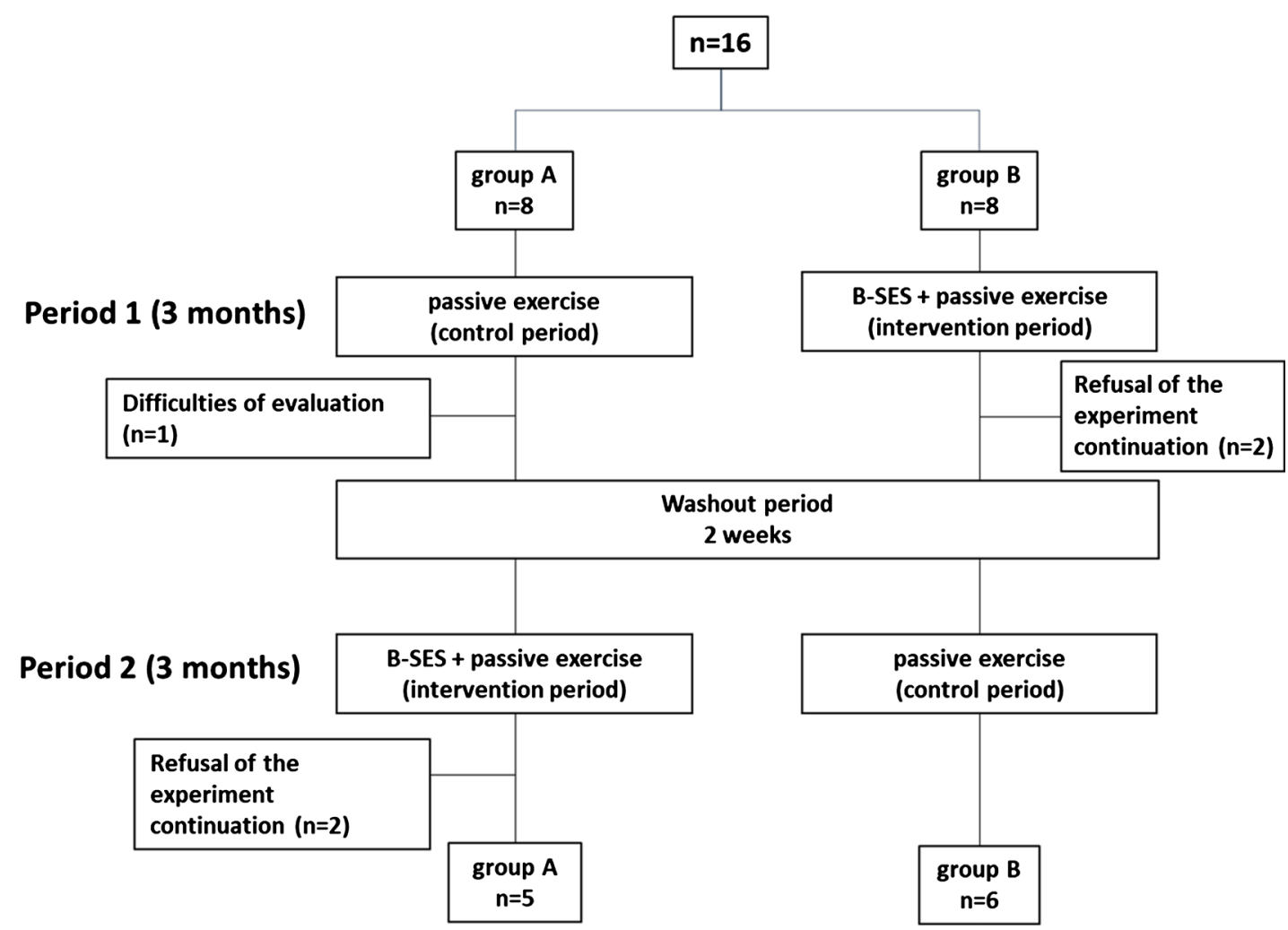

Figure 2. Design and flow of participants through the trial.

Table 3. Patients' characteristics included to examine the long-term effect of B-SES.

\begin{tabular}{|c|c|c|c|c|}
\hline & & $\begin{array}{c}\text { Total } \\
\text { Mean } \pm \text { SD/n }\end{array}$ & $\begin{array}{c}\text { Group A } \\
\text { Mean } \pm \text { SD/n }\end{array}$ & $\begin{array}{c}\text { Group B } \\
\text { Mean } \pm \text { SD/n }\end{array}$ \\
\hline & Age & $83.1 \pm 6.0$ & $84.4 \pm 4.3$ & $82 \pm 7.3$ \\
\hline \multicolumn{2}{|c|}{ Gender (men/women) } & 11 & $2 / 3$ & $2 / 4$ \\
\hline \multicolumn{2}{|r|}{ BMI $\left(\mathrm{kg} / \mathrm{m}^{2}\right)$} & $16.3 \pm 2.0$ & $16.6 \pm 1.8$ & $16.0 \pm 2.3$ \\
\hline \multirow[t]{3}{*}{ Disease } & Cerebral infarction & 9 & 4 & 5 \\
\hline & Cerebral hemorrhage & 1 & 1 & 0 \\
\hline & Subarachnoid hemorrhage & 1 & 0 & 1 \\
\hline \multirow{2}{*}{$\begin{array}{c}\text { Nutrition } \\
\text { management }\end{array}$} & Enteral nutrition (oral/tube) & 11 & $0 / 5$ & $2 / 4$ \\
\hline & Parenteral nutrition & 0 & 0 & 0 \\
\hline \multicolumn{2}{|c|}{ Length of hospitalization (days) } & $1496.7 \pm 1042.8$ & $1567 \pm 756.8$ & $1438.2 \pm 1306.8$ \\
\hline
\end{tabular}

Abbreviations: SD: standard deviation; BMI: body mass index. 
Carryover effect was not observed for any outcome measures. Treatment effects were present for all outcome measures. Period effect was present only in MAS and ROM of knee flexion (Table 4).

During the B-SES intervention period (irrespective of the phase), the mean ( \pm SD) change of the ROM from baseline to 3 months was $5.0^{\circ} \pm 7.6^{\circ}, 3.7^{\circ} \pm 7.6^{\circ}$, $3.0^{\circ} \pm 5.5^{\circ}, 2.6^{\circ} \pm 7.2^{\circ}$, and $5.4 \pm 3.8 \mathrm{~cm}$ for hip flexion, hip abduction, knee flexion, knee extension, and distance of knee, respectively. The Friedman test showed statistical differences and the post-hoc test results are presented in Table 5. The Friedman test revealed a significant difference in these values during the B-SES intervention period. The post-hoc test showed that ROM at 3 months increased significantly from the baseline value in hip flexion $(\mathrm{p}=0.014)$, hip abduction $(\mathrm{p}=0.043)$, and knee distance $(\mathrm{p}=0.001)$. The mean \pm SD change of the MAS from baseline to 3 months was $-0.82 \pm 1.47$ points, $-0.91 \pm 1.74$ points, $-1.00 \pm 1.38$ points, $-0.64 \pm 1.05$ points, and $-0.91 \pm 1.14$ points for hip flexion, hip abduction, knee flexion, knee extension, and distance of knee, respectively. The Friedman test showed statistical differences and the post-hoc test results are presented in Table 5. The Friedman test revealed a significant difference in these values during the B-SES intervention period. The post-hoc test showed that the MAS score at 3 months was significantly lower than the baseline value only in hip abduction $(\mathrm{p}=0.025)$.

During the control period, the mean $( \pm S D)$ change of the ROM from baseline to 3 months was $-0.4^{\circ} \pm 9.2^{\circ},-0.2^{\circ} \pm 4.4^{\circ}, 1.5^{\circ} \pm 14.7^{\circ},-3.3^{\circ} \pm 9.3^{\circ}$, and $-0.7 \pm$ $5.0 \mathrm{~cm}$ for hip flexion, hip abduction, knee flexion, knee extension, and distance of knee, respectively. The Friedman test showed statistical differences and the post-hoc test results are presented in Table 6 . The Friedman test revealed a significant

Table 4. Carryover, period effect, and treatment for the crossover study.

\begin{tabular}{|c|c|c|c|}
\hline & $\begin{array}{c}\text { Carryover effect/ } \\
\text { p value }\end{array}$ & $\begin{array}{c}\text { Treatment effect/ } \\
\text { p value }\end{array}$ & $\begin{array}{c}\text { Period effect/ } \\
\text { p value }\end{array}$ \\
\hline \multicolumn{4}{|l|}{ ROM } \\
\hline Hip flexion & $14.50 / 0.303$ & $5.333 / 0.005^{\star}$ & $0.333 / 0.847$ \\
\hline Hip abduction & $0.450 / 0.949$ & $4.808 / 0.0002^{\star}$ & $1.891 / 0.090$ \\
\hline Knee flexion & $3.083 / 0.810$ & $2.958 / 0.005^{\star}$ & $2.458 / 0.017^{\star}$ \\
\hline Knee extension & $20.63 / 0.341$ & $5.650 / 0.001^{\star}$ & $0.650 / 0.669$ \\
\hline Knee distance & $5.233 / 0.717$ & $5.550 / 0.0005^{\star}$ & $1.050 / 0.340$ \\
\hline \multicolumn{4}{|l|}{ MAS } \\
\hline Hip flexion & $0.116 / 0.914$ & $0.358 / 0.007^{\star}$ & $0.441 / 0.110$ \\
\hline Hip abduction & $1.000 / 0.421$ & $0.816 / 0.007^{\star}$ & $0.016 / 0.952$ \\
\hline Knee flexion & $1.350 / 0.052$ & $0.541 / 0.017^{\star}$ & $0.458 / 0.039^{*}$ \\
\hline Knee extension & $0.033 / 0.967$ & $0.566 / 0.020^{*}$ & $0.233 / 0.314$ \\
\hline Knee distance & $0.800 / 0.644$ & $1.300 / 0.006^{\star}$ & $0.700 / 0.088$ \\
\hline
\end{tabular}

${ }^{*} \mathrm{p}<0.05$, Abbreviations: ROM: range of motion; MAS: modified Ashworth scale. 
Table 5. Long-term effect of B-SES in addition to passive exercise for ROM and MAS.

\begin{tabular}{|c|c|c|c|c|c|c|}
\hline & & BL & Week 4 & Week 8 & Week 12 & $\begin{array}{l}\text { Friedmann test } \\
\quad \text { ( } p \text { value })\end{array}$ \\
\hline \multicolumn{7}{|l|}{ ROM } \\
\hline & Mean & 97.7 & 101.6 & $103.2^{\#}$ & $102.7^{\#}$ & \\
\hline \multirow{3}{*}{$\begin{array}{c}\text { Hip } \\
\text { Flexion }\left(^{\circ}\right)\end{array}$} & SD & 3.3 & 3.6 & 3.6 & 3.6 & 0.001 \\
\hline & $95 \% \mathrm{CI}$ & $90-110$ & $95-110$ & $95-115$ & $95-115$ & \\
\hline & Mean & 19.3 & 21.4 & 21.6 & $23.0^{\#}$ & \\
\hline \multirow{3}{*}{$\frac{\text { Hip }}{\text { abduction }\left(^{\circ}\right)}$} & SD & 2.1 & 2.0 & 2.0 & 1.8 & 0.015 \\
\hline & $95 \% \mathrm{CI}$ & $15-25$ & $15-30$ & $15-25$ & $20-25$ & \\
\hline & Mean & 142.7 & 143.6 & 144.6 & 145.7 & \\
\hline \multirow{3}{*}{$\begin{array}{c}\text { Knee } \\
\text { flexion }\left(^{\circ}\right)\end{array}$} & SD & 3.4 & 3.1 & 3.1 & 3.1 & 0.014 \\
\hline & $95 \% \mathrm{CI}$ & $140-150$ & $140-150$ & $140-155$ & $145-155$ & \\
\hline & Mean & -31.8 & -31.8 & -30.4 & -29.2 & \\
\hline \multirow{3}{*}{$\begin{array}{c}\text { Knee } \\
\text { extension }\left(^{\circ}\right)\end{array}$} & SD & 5.1 & 5.2 & 5.4 & 5.3 & 0.045 \\
\hline & $95 \% \mathrm{CI}$ & $-45--15$ & $-45--10$ & $-40--10$ & $-40--10$ & \\
\hline & Mean & 36.5 & 40.9 & $42.0^{\#}$ & $42.5^{\#}$ & \\
\hline \multirow{2}{*}{$\begin{array}{c}\text { Knee distance } \\
(\mathrm{cm})\end{array}$} & SD & 3.6 & 3.5 & 3.6 & 3.4 & 0.001 \\
\hline & $95 \% \mathrm{CI}$ & $26-48$ & $29-54$ & $30-53$ & $33-55$ & \\
\hline \multicolumn{7}{|l|}{ MAS } \\
\hline \multirow{3}{*}{$\begin{array}{c}\text { Hip } \\
\text { Flexion }\end{array}$} & Mean & 1.7 & 1.3 & 1.0 & 0.9 & \\
\hline & SD & 0.4 & 0.3 & 0.3 & 0.3 & 0.012 \\
\hline & $95 \% \mathrm{CI}$ & $0-4$ & $0-3$ & $0-2$ & $0-1$ & \\
\hline \multirow{3}{*}{$\begin{array}{c}\text { Hip } \\
\text { abduction }\end{array}$} & Mean & 2.7 & 2.3 & 2.1 & $1.8^{\#}$ & \\
\hline & SD & 0.3 & 0.3 & 0.3 & 0.3 & 0.002 \\
\hline & $95 \% \mathrm{CI}$ & $1-4$ & $1-4$ & $1-4$ & $1-4$ & \\
\hline \multirow{3}{*}{$\begin{array}{l}\text { Knee } \\
\text { flexion }\end{array}$} & Mean & 1.2 & 0.8 & 0.3 & 0.2 & \\
\hline & SD & 0.3 & 0.3 & 0.3 & 0.2 & 0.000 \\
\hline & $95 \% \mathrm{CI}$ & $0-3$ & $0-1$ & $0-0$ & $0-0$ & \\
\hline \multirow{3}{*}{$\begin{array}{c}\text { Knee } \\
\text { extension }\end{array}$} & Mean & 1.0 & 0.5 & 0.5 & 0.3 & \\
\hline & SD & 0.3 & 0.2 & 0.2 & 0.2 & 0.001 \\
\hline & $95 \% \mathrm{CI}$ & $0-2$ & $0-0$ & $0-0$ & $0-0$ & \\
\hline \multirow{3}{*}{$\begin{array}{c}\text { Knee } \\
\text { distance }\end{array}$} & Mean & 2.9 & 2.7 & 2.5 & 2.0 & \\
\hline & SD & 0.4 & 0.5 & 0.5 & 0.5 & 0.011 \\
\hline & $95 \% \mathrm{CI}$ & $1-4$ & $1-4$ & $1-4$ & $1-4$ & \\
\hline
\end{tabular}

\#, significant difference compared to BL. Abbreviations: BL: baseline; SD: standard deviation; $95 \% \mathrm{CI}$ : $95 \%$ confidence Interval; ROM: range of motion; MAS: modified Ashworth scale. 
Table 6. Long-term effect of passive exercise for ROM and MAS.

\begin{tabular}{|c|c|c|c|c|c|c|}
\hline & & BL & Week 4 & Week 8 & Week 12 & $\begin{array}{l}\text { Friedmann test } \\
\quad \text { ( } p \text { value })\end{array}$ \\
\hline \multicolumn{7}{|l|}{ ROM } \\
\hline \multirow{3}{*}{ Hip Flexion $\left({ }^{\circ}\right)$} & Mean & 97.7 & 97.5 & 97.9 & 97.4 & \multirow{3}{*}{0.880} \\
\hline & SD & 3.3 & 3.6 & 3.6 & 3.5 & \\
\hline & $95 \% \mathrm{CI}$ & $90-105$ & $90-110$ & $90-105$ & $90-110$ & \\
\hline \multirow{3}{*}{ Hip abduction $\left(^{\circ}\right)$} & Mean & 18.6 & 17.9 & 18.9 & 18.4 & \multirow{3}{*}{0.595} \\
\hline & SD & 2.1 & 2.0 & 2.0 & 1.8 & \\
\hline & $95 \% \mathrm{CI}$ & $15-25$ & $15-20$ & $15-25$ & $15-25$ & \\
\hline \multirow{3}{*}{ Knee flexion $\left(^{\circ}\right)$} & Mean & 141.0 & 143.0 & 143.2 & 142.5 & \multirow{3}{*}{0.834} \\
\hline & SD & 3.4 & 3.1 & 3.1 & 3.1 & \\
\hline & $95 \% \mathrm{CI}$ & $145-150$ & $145-150$ & $140-155$ & $140-155$ & \\
\hline \multirow{3}{*}{ Knee extension $\left({ }^{\circ}\right)$} & Mean & -31.5 & -30.9 & -35.5 & -34.8 & \multirow{3}{*}{0.020} \\
\hline & SD & 5.1 & 5.2 & 5.4 & 5.3 & \\
\hline & $95 \% \mathrm{CI}$ & $-50--15$ & $-40--15$ & $-50--15$ & $-50--10$ & \\
\hline \multirow{3}{*}{$\begin{array}{l}\text { Knee distance } \\
(\mathrm{cm})\end{array}$} & Mean & 37.7 & 38.5 & 37.3 & 37.0 & \multirow{3}{*}{0.397} \\
\hline & SD & 3.6 & 3.5 & 3.6 & 3.4 & \\
\hline & $95 \% \mathrm{CI}$ & $23-54$ & $28-52$ & $27-51$ & $26-50$ & \\
\hline \multicolumn{7}{|l|}{ MAS } \\
\hline \multirow{3}{*}{ Hip Flexion } & Mean & 1.3 & 1.1 & 1.3 & 1.2 & \multirow{3}{*}{0.760} \\
\hline & SD & 0.4 & 0.3 & 0.3 & 0.3 & \\
\hline & $95 \% \mathrm{CI}$ & $0-3$ & $0-2$ & $0-2$ & $0-2$ & \\
\hline \multirow{3}{*}{$\begin{array}{c}\text { Hip } \\
\text { abduction }\end{array}$} & Mean & 2.7 & 2.3 & 2.1 & 1.8 & \multirow{3}{*}{0.076} \\
\hline & SD & 0.3 & 0.3 & 0.3 & 0.3 & \\
\hline & $95 \% \mathrm{CI}$ & $2-4$ & $1-4$ & $1-3$ & $0-3$ & \\
\hline \multirow{3}{*}{$\begin{array}{l}\text { Knee } \\
\text { flexion }\end{array}$} & Mean & 0.6 & 0.6 & 0.7 & 0.7 & \multirow{3}{*}{0.739} \\
\hline & SD & 0.3 & 0.3 & 0.3 & 0.2 & \\
\hline & $95 \% \mathrm{CI}$ & $0-0$ & $0-1$ & $0-0$ & $0-1$ & \\
\hline \multirow{3}{*}{$\begin{array}{c}\text { Knee } \\
\text { extension }\end{array}$} & Mean & 0.8 & 0.6 & 1.0 & 0.9 & \multirow{3}{*}{0.207} \\
\hline & SD & 0.3 & 0.2 & 0.3 & 0.2 & \\
\hline & $95 \% \mathrm{CI}$ & $0-1$ & $0-1$ & $0-2$ & $0-1$ & \\
\hline & Mean & 2.6 & 3.0 & 2.5 & 3.4 & \multirow{3}{*}{0.128} \\
\hline $\begin{array}{c}\text { Knee } \\
\text { Distance }\end{array}$ & SD & 0.5 & 0.5 & 0.5 & 0.5 & \\
\hline & $95 \% \mathrm{CI}$ & $1-4$ & $2-4$ & $1-4$ & $2-4$ & \\
\hline
\end{tabular}

Abbreviations: BL: baseline; SD: standard deviation; 95\%CI: 95\% confidence Interval; ROM: range of motion; MAS: modified Ashworth scale. 
difference in only knee extension ROM values during the control period. However, the post-hoc test showed no significant differences. The mean \pm SD change of the MAS from baseline to 3 months was $-0.09 \pm 0.87$ points, $-0.55 \pm 0.96$ points, $-0.09 \pm 0.43$ points, $-0.09 \pm 0.68$ points, and $-0.73 \pm 1.62$ points for hip flexion, hip abduction, knee flexion, knee extension, and distance of knee, respectively. The Friedman test showed statistical differences and the post-hoc test results are presented in Table 6. The Friedman test revealed no significant difference in these values during the control period.

\section{Discussion}

The results of this study identified a statistically significant effect of B-SES when added to passive stretch on spasticity and contracture over passive exercise alone. In addition, this effect was observed in large portions of the lower extremities. The mechanisms by which electrical stimulation might bring about these improvements were not examined in this study; however, it has been suggested that electrical stimulation may reduce the resistance to passive range of motion [18] [19]. Our findings support the work of Khalili and colleagues [20] who employed electrical stimulation to the knee flexors of children with cerebral palsy and reported an increase in ROM and a decrease in hypertonia.

Our results show that an immediate effect of B-SES is a significant decrease in muscle tone. It is hypothesised that plastic effects within specific spinal cord circuitries (i.e. short-latency autogenic inhibition [Ib inhibition], recurrent inhibition from Renshaw cells, disynaptic reciprocal Ia inhibition, presynaptic inhibition of Ia terminals, and post-activation depression) may be associated with the reduced spasticity induced by treatments with neuromuscular electrical stimulation (NMES) [26]. A decrease in muscle tone may lead to an increasing ROM.

Our results of the long-term effect of B-SES in addition to passive exercise show a statistically significant decrease in muscle tone and increase in ROM compared to passive exercise alone. These results suggest that passive exercise only can maintain ROM but B-SES in addition to passive exercise can improve ROM. Although the usage of electrical stimulation with a frequency between 30 and $50 \mathrm{~Hz}$ combined with other treatments was associated with an increase of ROM in stroke patients [21], our results suggest that electrical stimulation of large portions of the lower extremities with a low frequency $(4 \mathrm{~Hz})$ combined with passive exercise can also bring about similar results. We previously investigated the effects of cyclic muscle twitch contraction $(1 \mathrm{~Hz}, 4 \pm 2 \mathrm{~mA}, 60$ min/day, 5 times/week) caused by NMES on immobilization-induced soleus muscle contracture in full plantar flexion with a plaster cast for 4 weeks in rats [27]. The results showed that cyclic muscle twitch contraction could decrease the progression of immobilization-induced restriction of dorsiflexion range of the ankle-joint motion. In addition, the expressions of fibrosis-related genes (i.e. hypoxia inducible factor- $1 \alpha$, transforming growth factor- $\beta 1, \alpha$-smooth muscle 
actin, and types I and III collagen), and fibrosis of perimysium and endomysium were significantly decreased by NMES. Thus, cyclic muscle twitch contraction induced by NMES might alleviate skeletal muscle fibrosis, reducing immobilization-induced muscle contracture. Repeated intervention with B-SES in addition to passive exercise may improve not only spasticity but also contracture of lower extremities.

The effect of B-SES in addition to passive exercise was statistically significant but marginal. Tseng et al. reported a $7^{\circ}-12^{\circ}$ improvement in ROM of the lower extremities of bedridden stroke patients using ROM exercise (4 weeks, twice-per-day, 6 days-per week) [16]. These patients had never received ROM before the study. However, all patients included in our study had already received rehabilitation consisting of passive exercise before the study. Thus, it is possible that there may be few improved elements as a result of our intervention. In addition, the effect of B-SES in addition to passive exercise intervention is not maintained in the long term, because no carryover effects were identified. We consider the cause of this result to be the lack of independent movement in the patients included in this study.

There are several limitations of this study. First, therapists and patients were not blinded. Second, the sample size was small. Third, the study design is a crossover design, thus, we need a randomized controlled trial to identify the effect of B-SES more clearly. In addition, the mechanism of improving ROM was not investigated, thus, we need electrophysiological and/ or histological observation to define this mechanism. Furthermore, the electrical stimulation delivered to the lower extremities was $4 \mathrm{~Hz}$, and it is possible that other frequencies of B-SES could produce different effects on MAS or ROM.

\section{Conclusion}

In conclusion, B-SES in addition to passive stretch has a more statistically significant effect on spasticity and contracture in large portions of the lower extremities of bedridden elderly patients than passive stretching alone. We consider B-SES a useful tool to improve the ROM of bedridden patients in LTC.

\section{Acknowledgements}

We wish to thank all of the study patients who completed the survey. Atsushi NAWATA (ALCARE Co., Ltd.) gave intellectual support for the B-SES procedure and maintenance.

\section{Conflicts of Interest}

The authors declare no conflicts of interest regarding the publication of this paper.

\section{References}

[1] Wagner, L.M., Capezuti, E., Brush, B.L., Clevenger, C., Boltz, M. and Renz, S. (2008) 
Contractures in Frail Nursing Home Residents. Geriatric Nursing, 29, 259-266. https://doi.org/10.1016/j.gerinurse.2007.09.002

[2] Wagner, L.M. and Clevenger, C. (2010) Contractures in Nursing Home Residents. Journal of the American Medical Directors Association, 11, 94-99.

https://doi.org/10.1016/j.jamda.2009.04.010

[3] Offenbächer, M., Sauer, S., Rieß, J., Müller, M., Grill, E., Daubner, A., Randzio, O., Kohls, N. and Herold-Majumdar, A. (2014) Contractures with Special Reference in Elderly: Definition and Risk Factors-A Systematic Review with Practical Implications. Disability and Rehabilitation, 36, 529-538. https://doi.org/10.3109/09638288.2013.800596

[4] Fischer, U., Müller, M., Strobl, R., Bartoszek, G., Meyer, G. and Grill, E. (2015) Prevalence of Functioning and Disability in Older Patients with Joint Contractures: A Cross-Sectional Study. European Journal of Physical and Rehabilitation Medicine, 51, 269-279.

[5] Gnass, I., Bartoszek, G., Thiesemann, R. and Meyer, G. (2010) Joint Contractures in Older Age. A Systematic Literature Review. Zeitschrift für Gerontologie und Geriatrie, 43, 147-157. https://doi.org/10.1007/s00391-009-0089-6

[6] Fergusson, D., Hutton, B. and Drodge, A. (2007) The Epidemiology of Major Joint Contractures: A Systematic Review of the Literature. Clinical Orthopaedics and Related Research, 456, 22-29. https://doi.org/10.1097/BLO.0b013e3180308456

[7] Lance, J.W. (1980) The Control of Muscle Tone, Reflexes, and Movement: Robert Wartenberg Lecture. Neurology, 30, 1303-1313.

https://doi.org/10.1212/WNL.30.12.1303

[8] Botte, M.J., Nickel, V.L. and Akeson, W.H. (1988) Spasticity and Contracture: Physiologic Aspects of Formation. Clinical Orthopaedics and Related Research, 233, 7-18. https://doi.org/10.1097/00003086-198808000-00003

[9] Burridge, J.H., Wood, D.E., Hermens, H.J., Voerman, G.E., Johnson, G.R., van Wijck, F., Platz, T., Gregoric, M., Hitchcock, R. and Pandyan, A.D. (2005) Theoretical and Methodological Considerations in the Measurement of Spasticity. Disability and Rehabilitation, 27, 69-80. https://doi.org/10.1080/09638280400014592

[10] Sommerfeld, D.K., Eek, E.U., Svensson, A.K., Holmqvist, L.W. and von Arbin, M.H. (2004) Spasticity after Stroke: Its Occurrence and Association with Motor Impairments and Activity Limitations. Stroke, 35, 134-139.

https://doi.org/10.1161/01.STR.0000105386.05173.5E

[11] Farmer, S.E. and James, M. (2001) Contractures in Orthopaedic and Neurological Conditions: A Review of Causes and Treatment. Disability and Rehabilitation, 23, 549-558. https://doi.org/10.1080/09638280010029930

[12] Lieber, R.L., Steinman, S., Barash, I.A. and Chambers, H. (2004) Structural and Functional Changes in Spastic Skeletal Muscle. Muscle Nerve, 29, 615-627. https://doi.org/10.1002/mus.20059

[13] Mollinger, L.A. and Steffen, T.M. (1993) Knee Flexion Contractures in Institutionalized Elderly: Prevalence, Severity, Stability, and Related Variables. Physical Therapy, 73, 437-444. https://doi.org/10.1093/ptj/73.7.437

[14] Grover, J., Gellman, H. and Waters, R.L. (1996) The Effect of a Flexion Contracture of the Elbow on the Ability to Transfer in Patients Who Have Quadriplegia at the Sixth Cervical Level. The Journal of Bone and Joint Surgery. American Volume, 78, 1397-1400. https://doi.org/10.2106/00004623-199609000-00016

[15] Ada, L., O’Dwyer, N. and O’Neill, E. (2006) Relation between Spasticity, Weakness 
and Contracture of the Elbow Flexors and Upper Limb Activity after Stroke: An Observational Study. Disability and Rehabilitation, 28, 891-897. https://doi.org/10.1080/09638280500535165

[16] Tseng, C.N., Chen, C.C., Wu, S.C. and Lin, L.C. (2007) Effects of a Range-of-Motion Exercise Programme. Journal of Advanced Nursing, 57, 181-191. https://doi.org/10.1111/j.1365-2648.2006.04078.x

[17] Harvey, L.A., Katalinic, O.M. and Herbert, R.D. (2017) Stretch for the Treatment and Prevention of Contracture: An Abridged Republication of a Cochrane Systematic Review. Journal of Physiotherapy, 63, 67-75.

https://doi.org/10.1016/j.jphys.2017.02.014

[18] Oo, W.M. (2014) Efficacy of Addition of Transcutaneous Electrical Nerve Stimulation to Standardized Physical Therapy in Subacute Spinal Spasticity: A Randomized Controlled Trial. Archives of Physical Medicine and Rehabilitation, 95, 2013-2020. https://doi.org/10.1016/j.apmr.2014.06.001

[19] Ping Ho Chung, B. and Kam Kwan Cheng, B. (2010) Immediate Effect of Transcutaneous Electrical Nerve Stimulation on Spasticity in Patients with Spinal Cord Injury. Clinical Rehabilitation, 24, 202-210. https://doi.org/10.1177/0269215509343235

[20] Khalili, M.A. and Hajihassanie, A. (2008) Electrical Simulation in Addition to Passive Stretch Has a Small Effect on Spasticity and Contracture in Children with Cerebral Palsy: A Randomised Within-Participant Controlled Trial. Australian Journal of Physiotherapy, 54, 185-189. https://doi.org/10.1016/S0004-9514(08)70025-4

[21] Stein, C., Fritsch, C.G., Robinson, C., Sbruzzi, G. and Plentz, R.D. (2015) Effects of Electrical Stimulation in Spastic Muscles after Stroke: Systematic Review and Meta-Analysis of Randomized Controlled Trials. Stroke, 46, 2197-2205. https://doi.org/10.1161/STROKEAHA.115.009633

[22] Miyamoto, T., Kamada, H., Tamaki, A. and Moritani, T. (2016) Low-Intensity Electrical Stimulation Induces Significant Increases in Muscle Strength and Cardiorespiratory Fitness. European Journal of Sport Science, 16, 1104-1110. https://doi.org/10.1080/17461391.2016.1151944

[23] Rockwood, K., Song, X., MacKnight, C., Bergman, H., Hogan, D.B., McDowell, I. and Mitnitski, A. (2005) A Global Clinical Measure of Fitness and Frailty in Elderly People. Canadian Medical Association Journal, 173, 489-495.

https://doi.org/10.1503/cmaj.050051

[24] Bohannon, R.W. and Smith, M.B. (1987) Interrater Reliability of a Modified Ashworth Scale of Muscle Spasticity. Physical Therapy, 67, 206-207. https://doi.org/10.1093/ptj/67.2.206

[25] Park, J., Seo, D., Choi, W. and Lee, S. (2014) The Effects of Exercise with TENS on Spasticity, Balance, and Gait in Patients with Chronic Stroke: A Randomized Controlled Trial. Medical Science Monitor, 20, 1890-1896. https://doi.org/10.12659/MSM.890926

[26] Motta-Oishi, A.A., Magalhães, F.H. and Mícolis de Azevedo, F. (2013) Neuromuscular Electrical Stimulation for Stroke Rehabilitation: Is Spinal Plasticity a Possible Mechanism Associated with Diminished Spasticity? Medical Hypotheses, 81, 784-788. https://doi.org/10.1016/j.mehy.2013.08.013

[27] Yoshimura, A., Sakamoto, J., Honda, Y., Kataoka, H., Nakano, J. and Okita, M. (2017) Cyclic Muscle Twitch Contraction Inhibits Immobilization-Induced Muscle Contracture and Fibrosis in Rats. Connective Tissue Research, 58, 487-495. https://doi.org/10.1080/03008207.2016.1257004 